\title{
The Impact of Investors Overconfidence on Trading Activities and Stock Returns in Pakistan Stock Exchange
}

\author{
MUHAMMAD TAHIR KHAN \\ Lecturer, Institute of Buisness Studies and Leadership \\ Abdul Wali Khan University Mardan \\ mtahir@awkum.edu.pk \\ GHAYYUR QADIR \\ Lecturer, Institute of Buisness Studies and Leadership \\ Abdul Wali Khan University Mardan \\ ghayyurqadir@awkum.edu.pk \\ SHAH RAZA KHAN \\ Iqra Naional University, Pesahwar \\ ABDUL LATIF \\ Demonstrator and PhD Scholar, Institute of Buisness Studies and Leadership \\ Abdul Wali Khan Uiversity, Mardan \\ Abdullatif89@gmail.com
}

\begin{abstract}
This study investigates the hypothesis of investor overconfidence that impact stock activity and stock return, using vector auto regressive model. Data observed consist of Monthly and daily returns from PSX 100 index. The results of the study shows that there are specific months in which the variables respond to each other or they are some actions that appears after some interval or else there is no significant relationship of current monthly return to past months volume, volume with volatility in stock returns as it is not increased with increase in volume. And there is no relationship of current monthly volume with previous market returns, Investor overconfidence has negative impact on trading activity as it keep them high and exaggerated level as it is not the real value of the securities and it may harm the investors. The results further marked that immediate past month return has an impact on current trading activity that is denoted from volume of trade.
\end{abstract}

Keywords: Investor Overconfidence, Stock Return, Trading Activity

\section{Introduction}

Many events have significant impact on stock exchange and its trading activities such as US stock market crash 1929, Asian crisis 1990,s earthquake of 2005, event of 12 may 2007 in Pakistan, the bullish market in regime of Musharaf 2007 than 2010, and bearish in 2008 -09 all these issues have impact on stock activities, prices and behavior of investors. Human beings are diverse all over the world and they all act differently 
according to their knowledge, mental level and other psychological factors in different scenarios of life. And their various acts are because they are put up with different psychological characteristics, financial, social and economical status including gender. All these factors contribute towards making decision in stock market and decisions are impacted by them as investors and their behavior. This impact some time become positive and some time affect the investors negatively. The negative impact is that people make the same mistake again and again while positive impact is that these psychological factors make them more confident if they have achieved good result. (Barberis and Thaler, 2001).These anomalies are hard to explain, the best way to explain, is to study behavioral finance. Some psychological components that are important and effect trading activity, influence decision making is Past experience, Individual differences, Age, Cognitive biases, Self attributes, Socioeconomic status (SES), Heuristic role, Overconfidence, Gender and Personal belief relevance. Traditional finance theories consist of the view that all investors participating in market are rational. But, now modern finance theories come with different perception that all investors playing role in markets are not rational and they have some characteristics of biases, irrationality and sentiments. The role of stock market in the social and general life of common individual who are participants in stock market is very significant in financial aspects. Since the households see the securities as source of income generating assets.

Theoretically stock market is a source for allocating the income of different participants in different time span in a proper way. Therefore individuals who can bear meager risk should participate to some extent in stock market. Rational investment in securities increases the financial status of household participating in market for long. As per the survey conducted in china the average community takes part in investment markets by only $17.5 \%$ (Wang and Liao).The very near results of stock market participation can also be seen in developed countries as in year 2010 America at the rate of 15\% survey conducted in 2012 (Bricker et al). The overconfident investors are more likely to participate in stock market (Tian Xia Zhengwai Wang kunpenli) 2013.Distinctive features in behavior and personalities of investors are main characteristic that persuades them to act differently from each other and make decisions in stock market differently and in their routine life as well. For this very purpose behavioral finance keeps them in concentration which affects them in their decision making associated with stock market. Hence concentrating on investors feeling is the key to comprehend the behavior of today's securities exchanges and investors. Getting thorough information of investor feelings by diving into the variables that add to it, evaluating them and how they influence judgment is of foremost significance in the exploration of today investors of stock market. The most intense element in this connection is investors' overconfidence. Overconfidence is when investors think about his personal knowledge and information to be more accurate in choosing the best stock and best time to exhibit trading and exit from security market shown in the result of Terrence odean.The evidence of the study is already been documented on the behavior biases of overconfidence in behavioral finance theory. The different views about the topic make it more interesting. 


\subsection{Overconfidence and its Impact}

Overconfidence mean the behavior of investor of self attribution and having perception that he have more reliable and accurate knowledge, which will lead him to aggressive trading in market and in response the return becomes inferior for the reason of irrational behavior. Larger returns of stock incline investors to be overconfident and in reaction, these investors trade more frequently (Ilyas \& Faheem, 2014). Every human being is loss averse as well every investor they tend to maximize their wealth and ride of loss. There is positive relationship between overconfidence of CEO and taking risky investment decisions (Malmendier \& Tate). Overconfident personalities are more positive and optimistic concerning the consequences generated through their actions (Moore and Healy). As larger quantity of study reveals that investors who are rational keep and hold those securities with themselves which will cause loss for them in that specific period of time while sell out those stocks which make them profitable on their sale at that particular point in time this was empirically demonstrated by Barber and Odean $(2000,2001,2002)$ and Odean (1998, 1999). Benosin 1998 have argued in their result that overconfident investors have assurance in their judgments on which they relay however they are not as precise in real. He has further shown in their results that overconfident personalities in security markets leads to higher transactions, volume of trade larger depth more unstable and more information prices. Beside this basic normal return most investor do invest in stock market to do better and to get rich quicker. Due to such genuine reasons they trade more frequently and positive returns on investment decisions make them to be more optimistic and overconfident (Barber \& Odean, 2001). Conducted study based on high overconfidence of investors the trading activities increases and price rise more regularly. Interaction between overconfidence and high returns shows that high returns intends investors even to be more overconfident (Inaishi, Toya, Zhai \& Kita, 2010). Accordingly examining the Pakistani investors (Bashir et al, 2013) exhibits in their study that how these biases of investors interrupt and impact the financial decisions made by them their result implies that there is significant impact of overconfidence and undue optimism on the investor's decisions. (Sultana \& Pardhasaradhi)Investors and their decisions are commanded by investor behavior that can be very important and crucial for financial gain of investors in the future. (Chen et al, 2007) Identified three essential psychological factors consist of overconfidence behavior, loss aversion that carry them to disposition effect they argues that market participants mostly depend on the returns generated by their securities in past and use them as for future formation of wealth on securities.

\subsection{Overconfidence Traits and its Consequences}

sOverconfident investors trade in moderate manners that might lead to poor performance overtime. Overconfident investors take more risk as they overestimate their abilities which has an impact on portfolio performance. Overconfident investors are not as much risk averse, giving preference to risk leads to an under diversified portfolio. Overconfident investor overvalues his own abilities and undervalues the available information. Presented information might indicate not to invest but overconfident investor will invest irrespective of projected negative gains. Previous study provides evidence of the impact of overconfidence on stock trading activities of investors they argues that they have impact on stock returns supported by above researchers. Over 
confidence is the over precision and over estimation some time refers to miss calibration, it is the belief that one knows more than he truly does.

\subsection{Research Problem}

Many study on this issue has been done by researchers such as (Beenish and Tariq, 2013; Hoffman and Thomas, 2013; Ilyas and Fahim 2014) and more have been through this in different countries and in different interval. To investigate that this impact exists in Pakistan we are carrying the study considering Pakistan stock exchange 100 index our sample period is ten years from 2005-2015. This research is about behavioral finance and utmost heed is paid to overconfidence, the psychological behavior of investors and the impact of this behavior on stock return and trading turnover of securities.

\subsection{Research Question}

What is the impact of overconfidence of investors on trading activities and stock returns in Pakistan stock exchange 100 indexes for the time period 2005-2015?

\subsection{Research Objectives}

This research study is directed to examine the impact of overconfidence on stock returns and trading activities.

\subsection{Significance of the Study}

This study is focusing on investor overconfidence and its impact on trading and stock returns, behavior in

trading activities. It will help investors as well managers to know about the behavior of Pakistani investor as well as behavior of stock markets in Pakistan.

\section{Literature Review}

Recent studies in behavioral finance reveal that financial decisions of investors depend upon numerous internal and external behavioral factors (Shefrin, 2000; Shlefier, 2000). (Sultana, 2010) An investment decision of individual is influenced by emotions and insensible biases that lead people to non-optimal decisions. Ilyas and Fahim, (2014) showing the impact of overconfidence on trading activity, constructing vector auto regressive model in their study argues that high returns of stock tend investors to be overconfident and in reaction, these investors trade more frequently. When one person having view in mind that he possess more abilities than he in real does is known as overconfidence said by (e.g., Campbell, Goodie, \& Foster, 2004; Lichtenstein et al., 1982; Yates, 1990). Overconfidence an important psychological bias, and analyzed the effect of overconfident investors behavior in security market using multi agent simulation. Overconfidence causes investors to be too certain about their own abilities and not to weight the opinion of others sufficiently. Overconfident investors apparently believe that they have superior information, even when this is not actually the case. Thus, the overconfidence hypothesis predicts that those investors will trade more who have perception that they have more knowledge from others and is more accurate, resulting in reduced returns (Inaishi, Toya, Zhai \& Kita, 2010). Fayyaz and Khalid (2012) conducting their study found significant positive response of turnover to market return shock while exhibiting their results. Odean (1998) argues that the high level of trading volume is the most important effect of overconfidence. 
Qadri (2014) the research has been conducted on questioner based survey in Islamabad Stock Exchange the majority of the respondents were males. They have checked the Impact of overconfidence and illusion control bias on investor's decision and found that the above two components of psychology is present in investors decision of Islamabad stock exchange and the decisions are more affected by them. People think that the wealth, knowledge and experience they have has big impact on the investment decisions. Overconfident investors in Islamabad stock exchange rapidly trade based on their skills, knowledge and experience. They have also shown that males are more confident than women and investor do not rely more on technical and fundamental analysis.

De Bondt et al., (1985) published a paper about behavioral finance in which they query about: "Does the stock market overreact?" the study provide evidence to support the hypothesis that cognitive bias (investor over- reaction) to a long series of bad news could produce predictable mispricing of stocks traded on the NYSE. Statman in his study argued that overconfidence bias is a driver of the disposition effect, because overconfidence traits motivate investors to trade irregularly between gains and losses Statman, (Thorley \& Vorkink, 2006). Benos (1998) states overconfident investors have faith in their judgments on which the relay but they are not as accurate in real. As abundance of study reveals that investors who are rational keep and hold losing stocks while sell winning this was empirically demonstrated by barber and Odean (2000, 2001, 2002) and Odean (1998, 1999).Statman, Thorley, and Vorkink (2006) present empirical evidence for the US market and argue that trading volume is higher after high returns, as investment success increases the degree of overconfidence.

Markus and Martin (2009) showed in their study that trading volume of an investor is exaggerated by past market return and past portfolio returns. Investor Psychology is a significant facet of behavioral finance (Shleifer \& Summers, 1990). Adel (2013) checked the relationship among bias, trading volume and volatility and the impact of overconfidence on investor's decision. They have used 27 companies as a sample listed in Tunis stock exchange observed for the period of 2002 to 2010. And the analysis has been conducted through vector auto regressive model and reported the importance of overconfidence in Tunisian stock market. Hassan, Khalid and Habib (2014) while using questionnaire for data collection, OLS and correlation method for the study argued that male and experience investors of men gender to be more over confident where as females and experience investors in them are usually more loss and risk avoiders while making investment decisions. Trinugroho (2011) in an experimental research work which combines both between and subject design. The partakers of the study were undergraduate students who have knowledge of financial management through their courses but they don't have practical experience of investing in security market. The main theme of their research work was to investigate the excessive trading hypothesis investors with higher overconfidence by high miss calibration level will be intended to practice trade aggressively and excessively. The result of the study argues that investors having high overconfidence will trade more and who have low confidence will trade less. They further argue that there is difference no between higher overconfident traders before the bad news and after while investors who have lower confidence level have difference between their post and pre trading activities after the speculation of bad news that is they 
have reduce their trading activities. And regarding returns the lower returns of high confident investors with respect to low confident investors.

Grinblatt and Keloharju (2009) argue in there result that one moment in confidence of investor is accompanied by four percent of increase in trading stock. With these result the researcher further studied the performance of overconfident investors in stock market and found negative relation between them that is lower portfolio performance of overconfident investors. Different researchers in their study have measure the overconfidence through various proxies like the above had measured it through high trading volume some from stock market participation and others like Barber and Odean in their study measured it through gender as they hypothesized that males are more overconfident then women. Tariq (2013) while exhibiting their research taking Pakistan stock market as a case and investigating the impact of overconfidence on stock return while considering 27 sample companies on daily bases to examine stock prices from 2003-2010 in Karachi stock exchange. They have used the vector auto regression model for measuring and analyzing the results. They had shown in their result that overconfidence is important for trading stock activity and monthly volume has no impact on returns. While monthly returns have impact on monthly volume. And monthly volume is not affected by monthly volatility while the monthly return is affected by volatility. Chungli (2009) Overconfidence has been focused in behavioral finance that how they affect trading activities from past. This paper investigates how overconfidence affects trader market properties. Their very initial result implies that overconfidence increases trade volume price distortion and volatility. Biais, Hilton, Mazurier and Pouget (2004) in their results argued that a form of tendency to underestimate the others information and overestimate the precision of oneself information being the traits of overconfident investors leads them to underestimate the sure uncertainty in valuating security and are expected to be especially vulnerable to the winner's curse.

We can find literature support in favor of overconfidence as well as against overconfident investors. Its critique argue that overconfident investors over look risk factors and over estimate their investment decisions, ignoring market realities that's why their active strategies make the market less efficient and give rise to excessive trading. While other argue that overconfident investors can help increase market efficiency because they spend most of their energy and resources to collect information. More ever considering the above argument, their overconfident personality makes them to trade more thus creating an arbitrage process which will help the securities to retain their original position. But the basic assumption is the level of overconfidence must not be too much high. These divergent views make this topic more interesting for researchers this paper is an attempt to define overconfidence bias and its relation with stock turnover and trading activity.

\subsection{Hypotheses}

In keeping view the question impact of investor's overconfidence on trading activities and stock returns in Pakistan stock exchange our hypothesis are:

H1: There is impact of overconfidence on trading activities.

H2: There is impact of overconfidence on stock return. 


\section{Research Methodology}

\subsection{Data Collection and Sampling}

The data collection is done through opendoors.pk, annual reports published on website of state bank of Pakistan and Pakistan stock exchange. The data is constituted of monthly and daily return of Pakistan stock exchange 100 indexes for ten years from 2005 to 2015 . The variation of psychological factor .i.e. overconfidence changes over monthly, weekly, daily and annually therefore we analyzed data of only monthly and daily observation because of time constraints. We have taken monthly volume for trading proxy and market capitalization to know about the turnover. We divided daily market trading values of 100 indexes to get daily market returns. PSX hold $90 \%$ of total market capitalization of the listed companies as it is a value weighted index of 100 companies. We have calculated monthly volatility while forming standard deviation of whole month day to day returns. That's the risk in securities and the variance that occur in returns of securities and trading activity. The data sample will consist of annual reports issued on websites Pakistan stock exchange 100 index, state bank of Pakistan and for some data we will be concerning to the opendoors.com. The time period of the data is ten years from 2005-2015. The research is of explanatory nature.

\subsection{Analysis Method}

\subsubsection{Vector Auto Regression}

This is a multi variant model in which one variable is taken as dependent and one or more than one are analyzed as independent variables and this model is auto regressive that regress its dependent variable automatically which shows that either the variable lagged value has an impact on itself. The model analyzes time series data, which are numerical numbers collected in regular interval over a period of time. This is an econometric model that converts theoretical data effect into numerical values. It shows the linear interdependencies among multiple time series. That is to check the past results and behavior has any impact on the current behavior. Current market returns have any dependency on previous or past month return. How volume and returns react to their past months lagged values. Either volatility is changed by volume and returns. To analyze this association of variables vector auto regressive model is best for getting significant results. Through this we forecast future trend in the market. In the model R square shows the percentage of change brought by independent variables in the dependent variable. The $p$ value of $f$ statistics shows the fitness of the model in percentage. The $t$ ratio and $p$ value for the variables show the significance level among the dependent and independent variable. The result will be significant if the $\mathrm{p}$ value in the result becomes lower than .05 and the $t$ ratio greater than 2 . On the other hand the result will be insignificant and there will be no relationship between the dependent and independent variable if the $p$ value is calculated more than .05 and $t$ ratio less than 2 .

\subsection{Model Specification}

$$
\text { Where }
$$

$$
\mathrm{Y}=\alpha+\beta 1 \mathrm{Y}_{\mathrm{t}-1}+\beta 1_{\mathrm{X} 1 \mathrm{t}-1+\beta 2 \mathrm{X} 2 \mathrm{t}-1+\mathrm{e}}
$$

$\mathrm{Y}_{=\text {it shows the variable taken as dependent in the equation. }}$

$\beta 1 \mathrm{Y}_{\mathrm{t}-1=\mathrm{It}}$ presents the independent variable

$\beta 1_{\mathrm{X} 1 \mathrm{t}-1=\mathrm{It}}$ represents other factor taken as independent variable and the $\mathrm{t}-1$ represents the lagged value of previous month. 
$\mathrm{t}-1=$ Tells the previous lag values taken up to six months for each variable such as

$\beta 1_{\mathrm{X} 1 \mathrm{t}-1+} \beta 1_{\mathrm{X} 1 \mathrm{t}-2+} \beta 1_{\mathrm{X} 1 \mathrm{t}-3+} \beta 1_{\mathrm{X} 1 \mathrm{t}-4+} \beta 1_{\mathrm{X} 1 \mathrm{t}-5+} \beta 1_{\mathrm{X} 1 \mathrm{t}-6 \text {. }}$

$\beta 2 \mathrm{X} 2 \mathrm{t}-1=$ shows the third factor taken as independent variable..

None of the variable is selected as exogenous and endogenous.

\subsection{Dependent Variable}

Overconfidence is taken as dependent variable. Trading volume is taken as proxy for measuring overconfident behavior of investors. Overconfidence increases when trading in a month or a day increases and decreases when trade becomes lower in given point in time.

\subsection{Independent Variable}

Monthly volume, monthly return, volatility and its lagged values are taken as independent variables.

\subsection{Data processing}

Monthly stock return was calculated on natural log of former values divided by initial values of PSX monthly return 100 Index. [= LN (Former value / Initial value)]. Market volume was taken as trading proxy from monthly volume data of open doors. Taken natural log of PSX daily return daily returns were constructed. Monthly volatility is calculated by taking standard deviation on daily return from first transaction to end transaction date of the months.

\section{Results and Discussions}

\begin{tabular}{|c|c|c|c|c|c|}
\hline $\begin{array}{l}\text { Monthly } \\
\text { Return }\end{array}$ & & $\begin{array}{l}\text { Monthly } \\
\text { Volatility }\end{array}$ & & $\begin{array}{l}\text { Monthly } \\
\text { Volume }\end{array}$ & \\
\hline Mean & 0.01302845 & Mean & 0.01157306 & Mean & 158.0586 \\
\hline $\begin{array}{l}\text { Standard } \\
\text { Deviation }\end{array}$ & 0.07761849 & $\begin{array}{l}\text { Standard } \\
\text { Deviation }\end{array}$ & 0.00666766 & $\begin{array}{l}\text { Standard } \\
\text { Deviation }\end{array}$ & 124.7565 \\
\hline Sample Variance & 0.00602463 & $\begin{array}{l}\text { Sample } \\
\text { Variance }\end{array}$ & 4.44577E-05 & $\begin{array}{l}\text { Sample } \\
\text { Variance }\end{array}$ & 15564.19 \\
\hline Range & 0.64665462 & Range & 0.03437126 & Range & 728.28 \\
\hline Minimum & -0.44879613 & Minimum & 7.37663E-05 & Minimum & 0 \\
\hline Maximum & 0.19785848 & Maximum & 0.03444503 & Maximum & 728.28 \\
\hline Count & 125 & Count & 125 & Count & 125 \\
\hline
\end{tabular}

In the above table over all statistics of the variable and there finding are expressed quantitatively. Mean shows the average level of the two variables monthly PSX return and monthly volatility in percentage form for ten year from time period 2005 to 2015. The values are expressed as $0.01302845,0.011557306$ for monthly return and volatility which shows the average value of return earned by PSX and monthly volatility. And the figure of monthly volume is shown in million rupees that have moved up to 158.058 million rupees, it is showing that from the period of 2005 to 2015 the mean value of volume is 158.058 million, and aggregate trade value in the ten year period remain on the specified figure in Pakistan stock market. The standard deviation shows the dispersion from the mean values and the change that occur in the variables on the average 
from its mean position with the passage of time in specified duration from 2005 to 2015 in the form of percentage for monthly PSX returns and monthly volatility. The values are placed as 0.07761849 and 0.00666766 which mean that deviation from mean position of PSX returns is $7.761 \%$ while the monthly volatility deviation takes place $0.666 \%$. This shows that the volatility has fluctuated from the mean value by $.0666 \%$ which shows that market remain volatile in this much percentage in these ten years. And the volume in same manners is expressed in million rupees i.e. it goes up or down from its mean value by an amount of 124.756 million rupees. The range in the descriptive statistics shows the limit of the variable in which it remains as a function of other variable thus it shows the difference between largest and smallest or maximum and minimum figure of the variable in the volume, volatility and return. The count in last row reports the total number of observation in the study that is 125 for the whole period of ten year from January 2005 to May 2015.

\subsection{Findings from Vector Auto Regression}

The main concern of the study was to analyze the impact of investor's behavior on stock return and the trading activities. For this very purpose we have selected the data time period from 2005 to 2015 and collected from different sources of open doors and Pakistan stock exchange web site. The data of our research is time series because we have analyzed one unit, Pakistan stock exchange for different time scales. Our data consist of monthly observations and the model used for processing was vector auto regression model. We have selected none of the variables as endogenous and exogenous and ran the model; the variables are monthly return in relation with volatility and volume, the relation of volatility with monthly return and volume, the association of volume with monthly return and volatility and at last the relation of current market return with its own past returns.

VAR system, lag order 6

OLS estimates, observations 2005:07-2015:05 $(\mathrm{T}=119)$

Log-likelihood $=-21.434974$

Determinant of covariance matrix $=0.00028776121$

$\mathrm{AIC}=1.3182$

$\mathrm{BIC}=2.6494$

$\mathrm{HQC}=1.8588$

Portmanteau test: LB (29) $=245.64, \mathrm{df}=207$ [0.0340]

Table 4.2: Monthly Return

\begin{tabular}{|llllll|}
\hline & Coefficient & Std. Error & t-ratio & p-value & \\
\hline Const & -0.00496603 & 0.0229374 & -0.2165 & 0.8290 & \\
MonthlyKSERetunn_1 & 0.0745062 & 0.111815 & 0.6663 & 0.5067 & \\
MonthlyKSEReturn_2 & -0.205377 & 0.111956 & -1.8344 & 0.0696 & $*$ \\
MonthlyKSEReturn_3 & 0.124832 & 0.108202 & 1.1537 & 0.2514 & \\
MonthlyKSEReturn_4 & 0.247356 & 0.118404 & 2.0891 & 0.0392 & $*$ \\
& & & & & $*$ \\
MonthlyKSEReturn_5 & 0.190748 & 0.114602 & 1.6644 & 0.0992 & $*$ \\
MonthlyKSEReturn_6 & 0.18407 & 0.111465 & 1.6514 & 0.1018 & \\
\hline Khan, Qadir, Khan \& Latif & & 23 & & ISSN: 2520-0739
\end{tabular}




\begin{tabular}{|c|c|c|c|c|c|}
\hline MonthlyVolatility_1 & 1.34893 & 1.60951 & 0.8381 & 0.4040 & \\
\hline MonthlyVolatility_2 & -1.23114 & 1.70344 & -0.7227 & 0.4715 & \\
\hline MonthlyVolatility_3 & 5.27822 & 1.7231 & 3.0632 & 0.0028 & * \\
\hline MonthlyVolatility_4 & -0.675885 & 1.63902 & -0.4124 & 0.6809 & \\
\hline MonthlyVolatility_5 & 1.59265 & 1.61087 & 0.9887 & 0.3252 & \\
\hline MonthlyVolatility_6 & -3.30588 & 1.48676 & -2.2235 & 0.0284 & $*$ \\
\hline MonthlyVolume_1 & 0.000256159 & 0.000100054 & 2.5602 & 0.0120 & $\begin{array}{l}* \\
*\end{array}$ \\
\hline MonthlyVolume_2 & $-2.13373 e-05$ & $9.83263 \mathrm{e}-05$ & -0.2170 & 0.8286 & \\
\hline MonthlyVolume_3 & $8.20486 \mathrm{e}-05$ & $9.65696 \mathrm{e}-05$ & 0.8496 & 0.3976 & \\
\hline MonthlyVolume_4 & -0.000244332 & $9.39794 \mathrm{e}-05$ & -2.5999 & 0.0107 & $\begin{array}{l}* \\
*\end{array}$ \\
\hline MonthlyVolume_5 & -0.000118999 & $8.66023 \mathrm{e}-05$ & -1.3741 & 0.1725 & \\
\hline MonthlyVolume_6 & $-8.75045 \mathrm{e}-05$ & $8.52787 \mathrm{e}-05$ & -1.0261 & 0.3073 & \\
\hline Mean dependent var & 0.012280 & \multicolumn{2}{|c|}{ S.D. dependent var } & 0.074979 & \\
\hline Sum squared resid & 0.505135 & \multicolumn{2}{|c|}{ S.E. of regression } & 0.071073 & \\
\hline R-squared & 0.238549 & \multicolumn{2}{|c|}{ Adjusted R-squared } & 0.101487 & \\
\hline $\mathrm{F}(18,100)$ & 1.740452 & \multicolumn{2}{|c|}{ P-value(F) } & 0.044266 & \\
\hline Rho & 0.058219 & \multicolumn{2}{|c|}{ Durbin-Watson } & 1.869228 & \\
\hline
\end{tabular}

F-tests of zero restrictions:

All lags of Monthly KSE Return F $(6,100)=2.6462$ [0.0201]

All lags of Monthly Volatility F $(6,100)=2.6187$ [0.0212]

All lags of Monthly Volume F $(6,100)=2.4407$ [0.0304] All vars, lag $6 \quad$ F (3, $100)=3.145[0.0285]$

R-Squared: $23.8 \%$

P-value of F (statistics):0.044266

$\mathrm{H}_{0}$ : The fit of model is not good.

$\mathrm{H}_{1}$ : The fit of model is not good.

The equation in the above table 01 shows that taking the monthly Pakistan stock exchange returns as dependent variable and others such as its lagged values as independent variables, volatility and volume.

\subsubsection{Sub Hypothesis}

HO: There is no impact on current monthly market return of its own previous values and the investors are not confident.

H1: There is impact on current monthly market returns of its own previous values and the investors are confident.

Taken the current market return in this stage as dependent and its own previous lagged values as independent variable, We will accept Ho if the $t$ ratio is lower than 2 and 
reject $\mathrm{H} 1$ and for $\mathrm{p}$ value we will accept Ho if $\mathrm{p}$ value is greater than .05 . The $\mathrm{P}$ values in result table are $0.5067,0.0696,0.2514,0.0392,0.0992$, and 0.1018 respectively from 1 to $6^{\text {th }}$ lag and t ratios respectively from 1 to $6^{\text {th }}$ are $0.6663,-1.8344,1.1537,2.0891,1.6644$ and 1.6514.Thus the table shows that monthly return has no relationship with its own previous lagged values in which from first to sixth past months are insignificant except $4^{\text {th }} /$ fourth month that is significant. That can be seen from lower $t$ ratios and higher $p$ values. We accepted our first hypothesis that investors are not overconfident and the investors do not make decisions while seeing the previous returns. The fit of model is good as shown above the $\mathrm{f}$ statistics value is less than .05 .

\subsubsection{Sub Hypothesis}

$H_{0:}$ There is no impact on current market return of previous monthly volatility and there is no relationship between them.

$H_{1:}$ There is impact on current market return of previous monthly volatility and there is relationship in them.

In monthly volatility equation lin above table, the result of previous two months is insignificant we have accepted Ho and rejected H1the $4^{\text {th }}$ and $5^{\text {th }}$ also give the same result but in $3^{\text {rd }}$ and $6^{\text {th }}$ the result shows that there is relationship among market return and volatility the result are significant and $\mathrm{H} 1$ is accepted as it can be seen from $\mathrm{t}$ ratios and $\mathrm{p}$ value. The $\mathrm{p}$ value for volatility in the above table from 1 to $6^{\text {th }}$ lag are given respectively as $0.8381,-0.7227,3.0632,-0.4124,0.9887,-2.2235$ and in sequence the $t$ ratios are as follow 1.60951,1.70344,1.7231,1.63902,1.61087,1.48676.

\subsubsection{Sub Hypothesis}

$H_{0}$ : There is no impact on current market returns of previous monthly volume and there is no relationship between them.

$H_{1}$ : There is impact on current market returns of previous monthly volume and there exist a relationship.

In monthly volume as independent variable with market return the results are insignificant as shown from higher $\mathrm{p}$ values in $2^{\text {nd }}, 3 \mathrm{rd}$, 5th and $6^{\text {th }}$ observation while significant in first and fourth observation in which the $\mathrm{H} 1$ is accepted and market return is affected by volume in these months. The ratios of $t$ in ascending order from 1 to 6 is as follow 2.5602,-0.2170,0.8496,-2.5999,-1.3741,-1.0261 and $p$ values are $0.0120,0.8286,0.3976,0.0107,0.1725,0.3073$ So we can say that the information diffusion is slow in the market and there is no relationship of market return and volume. The investors are not overconfident and they do not over react or over trade while seeing the previous volumes of trade in the market. 
Table 4.3: Monthly Volatility

\begin{tabular}{|llllll|}
\hline & Coefficient & Std. Error & t-ratio & p-value & \\
\hline Const & 0.00515899 & 0.00155613 & 3.3153 & 0.0013 & $* *$ \\
& & & & & $*$ \\
MonthlyKSEReturn_1 & -0.0153147 & 0.00758579 & -2.0189 & 0.0462 & $* *$ \\
MonthlyKSEReturn_2 & 0.00868085 & 0.00759537 & 1.1429 & 0.2558 & \\
MonthlyKSEReturn_3 & -0.0282672 & 0.00734071 & -3.8507 & 0.0002 & $* *$ \\
& & & & & $*$ \\
MonthlyKSEReturn_4 & -0.00193835 & 0.0080328 & -0.2413 & 0.8098 & \\
MonthlyKSEReturn_5 & -0.00602557 & 0.00777485 & -0.7750 & 0.4402 & \\
MonthlyKSEReturn_6 & -0.00238928 & 0.00756204 & -0.3160 & 0.7527 & \\
MonthlyVolatility_1 & 0.35842 & 0.109193 & 3.2824 & 0.0014 & $* *$ \\
& & & & & $*$ \\
MonthlyVolatility_2 & 0.0467891 & 0.115566 & 0.4049 & 0.6864 & \\
MonthlyVolatility_3 & -0.205309 & 0.116899 & -1.7563 & 0.0821 & $*$ \\
MonthlyVolatility_4 & -0.0624696 & 0.111195 & -0.5618 & 0.5755 & \\
MonthlyVolatility_5 & 0.0594162 & 0.109285 & 0.5437 & 0.5879 & \\
MonthlyVolatility_6 & 0.065682 & 0.100865 & 0.6512 & 0.5164 & \\
MonthlyVolume_1 & $5.27061 \mathrm{e}-06$ & $6.78787 \mathrm{e}-06$ & 0.7765 & 0.4393 & \\
MonthlyVolume_2 & $3.222 \mathrm{e}-07$ & $6.67069 \mathrm{e}-06$ & 0.0483 & 0.9616 & \\
MonthlyVolume_3 & $6.0556 \mathrm{e}-06$ & $6.55151 \mathrm{e}-06$ & 0.9243 & 0.3576 & \\
MonthlyVolume_4 & $1.44497 \mathrm{e}-05$ & $6.37578 \mathrm{e}-06$ & 2.2663 & 0.0256 & $*$ \\
MonthlyVolume_5 & $-3.12279 \mathrm{e}-06$ & $5.87531 \mathrm{e}-06$ & -0.5315 & 0.5962 & \\
\hline
\end{tabular}

\begin{tabular}{|c|c|c|c|}
\hline Mean dependent var & 0.010941 & S.D. dependent var & 0.005842 \\
\hline Sum squared resid & 0.002325 & S.E. of regression & 0.004822 \\
\hline R-squared & 0.422706 & Adjusted R-squared & 0.318793 \\
\hline $\mathrm{F}(18,100)$ & 4.067890 & P-value $(F)$ & $2.89 \mathrm{e}-06$ \\
\hline Rho & -0.013664 & Durbin-Watson & 2.024335 \\
\hline MonthlyVolume_6 & $-3.32992 \mathrm{e}-07$ & $5.78551 \mathrm{e}-06$ & 0.9542 \\
\hline
\end{tabular}

F-tests of zero restrictions:

All lags of Monthly KSE Return F $(6,100)=3.3212$ [0.0050]

All lags of Monthly Volatility F $(6,100)=2.8577$ [0.0130]

All lags of Monthly Volume F $(6,100)=2.6462$ [0.0201]

All vars, lag 6

$\mathrm{F}(3,100)=0.24807[0.8625]$

R-squared: $42 \%$

$\mathrm{P}$ value of F (Statistics): $2.89 \mathrm{e}^{-06}$

$\mathrm{H}_{0:}$ : The fit of model is not good.

$\mathrm{H}_{1}$ : The fit of model is good.

In table 2 in the above table the monthly volatility is taken as dependent variable and as independent variables market return, volatility, volume and its own lagged values of volatility are taken. 


\subsubsection{Sub Hypothesis}

$H_{0}$ : There is no current monthly volatility of previous market returns and there is no relationship between them.

$H_{1}$ : There is impact on current monthly volatility of previous market return and there is relationship between them.

First we have checked it with market return taken as independent variable. In which the $1^{\text {st }}$ and $3^{\text {rd }}$ are significant mean the volatility has shown the significant relationship with market return that can be seen from lower $\mathrm{p}$ value and higher $\mathrm{t}$ ratio.H1 is accepted and there is relationship and the monthly volatility is affected by previous market returns. There is immediate response for information flow as the immediate past month affected the current month volatility from previous month return. But from $2^{\text {nd }}$ to $6^{\text {th }}$ except the above two shows insignificant results mean that there is no relationship between monthly volatility and monthly returns. Here are the value of $\mathrm{p}$ depicted in result from 1 to $6^{\text {th }}$ lag $0.0462,0.2558,0.0002,0.8098,0.4402,0.7527$ and $t$ ratios respectively $-2.0189,1.1429,-3.8507,-0.2413,-0.7750,-0.3160$. Volatility shows the risk in securities so the current volatility with ups and downs in previous market return does not changes.

\subsubsection{Sub Hypothesis}

$H_{0}$ : There is no impact on current monthly volatility of its own previous lagged values therefore relationship does not exist.

$H_{1}$ : There is impact on current monthly volatility of its own previous lagged values therefore the relationship exists.

In the second phase we have taken the lag of monthly volatility, its self lagged values as independent variable and dependent also. That the very first result is shown as significant and from $2^{\text {nd }}$ to $6^{\text {th }}$ the result is insignificant as seen from higher value of $p$ and lower $t$ ratio. The ratios of $t$ in above result are as follow form 1 to $6^{\text {th }}$ lag $3.2824,0.4049$, $-1.7563,-0.5618,0.5437$ and 0.6512 . The values of $\mathrm{p}$ are given in same manner as $0.0014,0.6864,0.0821,0.5755,0.5879$, and 0.5164 . So the hypothesis Ho is accepted in them and there is no relationship between volatility and its own previous lags with current volatility except the immediate previous month. And this is not necessary that after every volatile month the next month will also be volatile.

\subsubsection{Sub Hypothesis}

$H_{0}$ : There is no impact on current monthly volatility of previous volume and the volume does not increase volatility.

$H_{1}$ : There is impact on current monthly volatility of previous volume therefore volume increases volatility.

Thirdly we have taken the volume as independent variable in relation with volatility. The result in table shows that there is insignificant relationship of volatility with volume. It tells us that there is no relationship of volatility and volume and the current volatility is not affected by previous volume of trading activity. As it is depicted in table from $1^{\text {st }}$ to $6^{\text {th }}$ month here Ho is accepted. While in $4^{\text {th }}$ month the result is significant and H1 is accepted here. The values of $\mathrm{p}$ are subsequently from 1 to $6^{\text {th }}$ lag $0.4393,0.9616,0.3576$, $0.0256,0.5962,0.9542$ and $t$ ratios are as follows $0.7765,0.0483,0.9243$, $2.2663,-0.5315$ and -0.0576 . We can say that volume of previous months does not affect 
volatility of current month and the volatility is not increased by trading volume.

Table 4.4: Monthly Volume

\begin{tabular}{|llllll|}
\hline & Coefficient & Std. Error & t-ratio & $p$-value & \\
\hline Const & 7.88835 & 24.7571 & 0.3186 & 0.7507 & \\
MonthlyKSEReturn_1 & 203.713 & 120.685 & 1.6880 & 0.0945 & $*$ \\
MonthlyKSEReturn_2 & -117.076 & 120.838 & -0.9689 & 0.3349 & \\
MonthlyKSEReturn_3 & -275.047 & 116.786 & -2.3551 & 0.0205 & $* *$ \\
MonthlyKSEReturn_4 & 12.6787 & 127.797 & 0.0992 & 0.9212 & \\
MonthlyKSEReturn_5 & -34.0468 & 123.693 & -0.2753 & 0.7837 & \\
MonthlyKSEReturn_6 & 68.0275 & 120.308 & 0.5654 & 0.5730 & \\
MonthlyVolatility_1 & 1256.76 & 1737.2 & 0.7234 & 0.4711 & \\
MonthlyVolatility_2 & -4243.86 & 1838.58 & -2.3082 & 0.0230 & $* *$ \\
MonthlyVolatility_3 & 1361.69 & 1859.8 & 0.7322 & 0.4658 & \\
MonthlyVolatility_4 & -3871.17 & 1769.05 & -2.1883 & 0.0310 & $* *$ \\
MonthlyVolatility_5 & 6064.87 & 1738.66 & 3.4882 & 0.0007 & $* * *$ \\
MonthlyVolatility_6 & 585.209 & 1604.71 & 0.3647 & 0.7161 & \\
MonthlyVolume_1 & 0.425374 & 0.107991 & 3.9390 & 0.0002 & $* * *$ \\
MonthlyVolume_2 & 0.0998858 & 0.106127 & 0.9412 & 0.3489 & \\
MonthlyVolume_3 & 0.263549 & 0.104231 & 2.5285 & 0.0130 & $* *$ \\
MonthlyVolume_4 & -0.0113737 & 0.101435 & -0.1121 & 0.9109 & \\
MonthlyVolume_5 & 0.0671153 & 0.0934727 & 0.7180 & 0.4744 & \\
MonthlyVolume_6 & -0.00391253 & 0.0920441 & -0.0425 & 0.9662 & \\
\hline
\end{tabular}

\begin{tabular}{|lcll|}
\hline Mean dependent var & 149.1782 & S.D. dependent var & 109.8258 \\
Sum squared resid & 588461.9 & S.E. of regression & 76.71127 \\
R-squared & 0.586546 & Adjusted R-squared & 0.512124 \\
F(18, 100) & 7.881368 & P-value(F) & $2.00 \mathrm{e}-12$ \\
Rho & -0.009208 & Durbin-Watson & 2.016255 \\
\hline
\end{tabular}

F-tests of zero restrictions:

All lags of Monthly KSE Return F $(6,100)=1.8584$ [0.0954]

All lags of Monthly Volatility F $(6,100)=4.3878$ [0.0006]

All lags of Monthly VolumeF $(6,100)=11.59$ [0.0000]

All vars, lag $6 \quad F(3,100)=0.14186[0.9347]$

For the system as a whole

Null hypothesis: the longest lag is 5

Alternative hypothesis: the longest lag is 6

Likelihood ratio test: Chi-square (9) $=13.4631$ [0.1427]

R-Squared: $58.6 \%$

$\mathrm{H}_{0=}$ The fit of model is not good.

$\mathrm{H}_{1=}$ The fit of model is good.

In table 03 the volume is taken as dependent variable and monthly return, volatility and volume its self as independent variables. 


\subsubsection{Sub Hypothesis}

$H_{0}$ : There is no impact on current volume of previous monthly market returns, the investors are not overconfident and the relationship does not exist.

$H_{l}$ : There is impact on current volume of previous monthly market returns, therefore investors are confident and there exists a relationship.

At first we have checked the monthly return as independent variable in relation with volume. In which the results are shown as insignificant from $1^{\text {st }}$ to $6^{\text {th }}$ month Ho is accepted. That can be seen from lower ratio of $t$ and higher value of $p$. The $p$ values are expressed from 1 to $6^{\text {th }}$ month are $0.0945,0.3349,0.9212,0.7837,0.5730$ and the $t$ ratios are placed in similar form as $1.6880,-0.9689,-2.3551,0.0992,-0.2753$, and 0.5654 . And it furtherpoints that there is no relationship between volume and market returns. The current trading volume is not affected by previous market returns. Except 3rd month result which signifies that there is relation between them and they are significant. And the investors are not overconfident in Pakistan stock market.

\subsubsection{Sub Hypothesis}

$H_{0}$ : There is no impact on current volume of the previous lagged volatility there is no relationship.

$H_{1}$ : There is impact on current volume of the previous lagged volatility and there is relationship between them.

Secondly we took the monthly volatility as independent variable in relation with volume. In which the $2^{\text {nd }}, 4^{\text {th }}$ and 5 th month results are significant and $\mathrm{H} 1$ is accepted that can be seen from lower of $p$ and higher value of $t$ ratio. The values of $p$ are provided from 1 to $6^{\text {th }}$ as $0.4711,0.0230,0.4658,0.0310,0.0007$ and 0.7161 . In the result the $t$ ratios are also given in same manner as $0.7234,-2.3082,0.7322,-2.1883,3.4882$, and 0.3647 .It shows that there is relationship between them. While the $1^{\text {st }}, 3 \mathrm{rd}$ and $6^{\text {th }}$ month results are of insignificant nature that tells us that there is no relationship between current monthly volume and volatility. And the current volume is not affected by previous month volatility. Here $\mathrm{H}_{0}$ is accepted because of higher value of $\mathrm{p}$ and lower ratio of $\mathrm{t}$ from 2 .

\subsubsection{Sub Hypothesis}

$H_{0}$ : There is no impact on current volume of its own previous lagged values and there is no relationship.

$H_{1}$ : There is impact on current volume of its own previous lagged values there is significant relationship.

At last stage we have taken the monthly volume as dependent and its own lagged values as independent variable for each other. In which the result shows that $1^{\text {st }}$ and $3^{\text {rd }}$ month are significant and the previous volume of these month affect the current trading volume. And there is relationship between them. For this result showing lower values of $p$ and higher ratio of $\mathrm{p} \mathrm{H}_{1}$ is accepted. The values of $\mathrm{p}$ from 1 to $6^{\text {th }}$ are expressed as $0.0002,0.3489,0.0130,0.9109,0.4744$, and 0.9662. And the in same sequence the $t$ ratios are sited as $3.9390,0.9412,2.5285,-0.1121,0.7180$ and -0.0425 . That shows that there is impact of previous values of volume on current trading volume. While the $2^{\text {nd }}$ to $6^{\text {th }}$ month the relationship is insignificant and there is no relationship between current volume and its previous lagged values. $\mathrm{H}_{0}$ is accepted here because the value of $\mathrm{p}$ is higher than .05 and the ratio of $t$ is lower than 2 . So we can say that the volume of current 
month is not affected by its own previous lagged values. As a whole we can say that the impact is seen from immediate past month on monthly volume from its lag month and it is possible that there is same event or factors that occur in $3^{\text {rd }}$ month again while not in proceeded months.

\subsection{Conclusion}

The whole study investigates the hypothesis of investor overconfidence that impact stock activity and stock return. We have documented further study in behavioral finance. For the development of theoretical aspect of investors' overconfidence its impact on trading activity and stock return and vice versa we have used vector auto regression model to carry out the study. As this study is consisted of multivariate variables so the said model is best to explain the result. The main aim is to know about the behavior of Pakistani investor in Pakistan stock exchange. Overconfidence is focused in the study one of its hypothesis postulates that overconfident leads to excessive and higher trading volume keeping in mind the assumption, the past return of security make the investor to be overconfident. The decisions of investors are made through psychological characteristics to trade in the security market or not. Which affect them in long run in both angles for positive we can say that the security purchased earn a big sum of money for them. On the other hand the affect can be negative as well that is it can cause huge sum of loss that may not be borne by the investor and can throw him out of the market.

The main focus is overconfidence and its impact in Pakistan stock exchange using vector auto regressive model. Data observed consist of Monthly and daily returns from PSX 100 index. Findings from the model shows that there are specific months in which the variables respond to each other or they are some actions that appears after some interval or else there is no significant relationship of current monthly return to past months volume, volume with volatility in stock returns as it is not increased with increase in volume. And there is no relationship of current monthly volume with previous market returns, Investor overconfidence has negative impact on trading activity as it keep them high and exaggerated level as it is not the real value of the securities and it may harm the investors. The results further marked that immediate past month return has an impact on current trading activity that is denoted from volume of trade. It is noticeable here that Pakistani investors consider the returns of security before investment and if they predict the return to be high they rush toward investment more over the investors know the full fundamental and technical information about the security or it's the unsatisfactory, inadequate knowledge and overconfidence.

\subsection{Recommendations}

In the light of this research and result we suggest that investors while making investment decision in stock market should be aware of the stock fundamental and technical information. Even if he knows the complete information still the psychological factors such as overconfidence impact their decision and return in some manners. In this research we have taken only few variables to check the impact and only in one country due to time and data constraints. Further research can be done while considering more variables such as GDP, exchange rate etc and more psychological factors should be consider for more countries. 


\section{References}

Adel, B. \& Mariem, T. (2013). The Impact of Overconfidence on Investors' Decisions. Business and Economic Research, 3(2), 53.

Barber, B. M. \& Odean, T. (2001). Boys will be boys: Gender, overconfidence, and common stock investment. Quarterly journal of Economics, 261-292.

Barber, B. M. \& Odean, T. (2011). The behavior of individual investors.Available at SSRN 1872211.

Biais, B., Hilton, D., Mazurier, K. \& Pouget, S. (2005). Judgemental overconfidence, self-monitoring, and trading performance in an experimental financial market. The Review of economic studies, 72(2), 287-312.

Bondt, W. F., \& Thaler, R. (1985). Does the stock market overreact? The Journal of finance, 40(3), 793-805.

Burks, S, V., Carpenter, J, P., Goetta, L. \& Rustichini, A. (2010). Overconfidence is Social Signaling Bias IZA DP No. 4840.

Chungli, Y. Z. (2009). Examining the Effect of Traders' Overconfidence on Market behavior, Department of Information Management.

Daniel, K. \& Hirshleifer, D. (2015). Overconfident Investors, Predictable Returns, and Excessive Trading. The Journal of Economic Perspectives, 29(4), 61-87.

Goetzmann, W. N., \& Massa, M. (2003). Disposition matters: volume, volatility and price impact of a behavioral bias (No. w9499). National Bureau of Economic Research.

Hoffmann, A. O., \& Post, T. (2013). How Does Investor Confidence Lead to Trading? Theory and Evidence on the Links between Investor Return Experiences, Confidence, and Investment Beliefs.

Inaishi, R., Toya, K., Zhai, F., \& Kita, E. (2010). Effect of Overconfident Investor Behavior to Stock Market. JACIII, 14(6), 661-668.

Shabbir, M. (n.a). An empirical study of Overconfidence and illusion of control biases, Impact on investor's decision making: An Evidence from ISE.

Shafi, M. (2014). Determinants Influencing Individual Investor Behavior in Stock Market: A Cross Country Research Survey. Arabian Journal of Business and Management Review, 2(1), 60-71.

Sindhu, M. I. \& Waris, F. (n.a). Overconfidence and turnover: Evidence from the Karachi Stock Exchange.

Tariq, B., \& Ullah, N. Investor Overconfidence and Stock Returns: Evidence from Pakistan.

Trinugroho, I., \& Sembel, R. (2011). Overconfidence and excessive trading behavior: An experimental study. International Journal of Business and Management, 6(7), 147.

Xia, T., Wang, Z., \& Li, K. (2014). Financial literacy overconfidence and stock market participation. Social Indicators Research, 119(3), 1233-1245.

Yasir, M. (2015). Attitude of Pakistan's Individual Investor towards Risk during Bull and Bear markets. VFAST Transactions on Education and Social Sciences, 5(2) 